\title{
Investigation of the relationship between alexithymia and eating attitude, self-esteem and anger in women who applied to psychological counseling center
}

\author{
Hüseyin Ünübol, Feride Gökben Hızlı Sayar, Sinem Kanpolat
}

Department of Psychology, Üsküdar University, Faculty of Humanities and Social Sciences, İstanbul, Turkey

DOI: $10.18621 /$ eurj.350423

\begin{abstract}
Objectives: The main purpose of this study was to examine self-esteem, anger and eating attitude with alexithymia in people who consult to the psychological counseling center. The sample of the study consist of 100 women who were located in Istanbul and applied to the psychological consulting center.

Methods: Consent form, demographic form, State-Trait Anger Expression Inventory, Rosenberg Self-Esteem Inventory, Toronto Alexithymia Scale and Eating Attitude Test have been used to collect the data in this study. In this research, the relationship between sociodemographic features, alexithymia, self-esteem, anger, eating attitude of women who consult to the psychological counseling center had been examined. Data obtained have been analyzed statistically by using SPSS 15.0 for Windows.

Results: The findings of this research supported our hypothesizes. Regarding the relationship between eating attitude and alexithymia, there is a positive relationship between difficulties in identifying and describing feelings with eating attitudes $(p<0.05)$. Regarding the relationship between alexithymia and self-esteem, there is a positive relation between sub-dimensions of alexithymia scale with subscales of self-esteem $(p<0.05)$. There is a positive relationship between identifying feelings with trait anger and anger-out scores $(p<0.05)$. Conclusions: According to these results, it appears that alexithymia has a serious relationship with anger, eating attitude and self-esteem. We suggest that alexithymia may be at the center of other features relations with each other.
\end{abstract}

Keywords: Alexithymia, eating attitude, anger, self-esteem

Received: November 11, 2017; Accepted: December 23, 2017; Published Online: March 14, 2018

\begin{abstract}
A lexithymia is a personality trait that is associated with a difficulty identifying and describing one's feelings, with difficulty in distinguishing between feelings and bodily sensations and with an externally focused, logical, thinking style [1]. Also, alexithymia is suggested to result in chronic sympathetic hyperarousal, physiological response, somatosensory amplification, and complaints of physical symptoms [2]. When one can not distinguish the emotional tension
\end{abstract}

experienced, this emotion can feel like anger. The relationship between alexithymia and anger has been evaluated by few studies providing evidence of a complex association between them. Compared to individuals in the low-alexithymia group, subjects in the high-alexithymia group exhibited more non-verbal anger [3]. Anger trait, as defined by Forgays et al. [4] is a tendency to experience angry feelings and is thought to be a relatively stable personality character-

Address for correspondence: Hüseyin Ünübol, MD., Assistant Professor, Üsküdar University, Faculty of Humanities and Social Sciences, Department of Psychology, Istanbul, Turkey

E-mail: huseyin.unubol@uskudar.edu.tr 
istic. A wider range of situations is easier to be perceived by individuals high in anger trait as anger eliciting. These people tend to experience more persistent anger during these situations than do individuals with low anger trait. The maladaptive form of aggression can be caused by poor awareness of emotions, alexithymia which is a diminished ability to think and talk about feelings [5], emotion dysregulation, and impulsivity. Those who do not know their emotions have difficulties in mitigating emotional awakening, especially under stress.

People may feel a sense of tension when they see a potential danger in their relational environment, and they may be deprived of appropriate strategies (e.g., to adopt appropriate communication and negotiating skills) to resolve possible interpersonal conflicts without recognizing the source and nature of this feeling. One of the most widely accepted conceptualizations is the lack of awareness of emotions and lack of comprehension, lack of understanding, acceptance of emotional reactions, difficulty in being in goal-oriented behavior when adversity, ability to avoid impulse responses while experiencing negative emotions, and limited effective emotional regulation strategies [6]. Research in recent years has shown that the challenges in these areas may increase the individual's tendency to react with aggression-perceived threats or crimes [7]. Indeed, even among people who fully realize their emotions, there is a certain variability in how they handle and organize them (e.g., rethinking the situation or thinking about different problem-solving strategies). For this reason, dysregulation of emotions, and especially anger, is considered a possible mechanism underlying aggression [8]. Emotional regulation processes and negative mood in particular play an important role in the development [9] and maintenance of binge eating disorder [10], although in children and adolescents findings are somewhat contradictory [11]. It was assumed that the negative impact came before and disappeared from inappropriate eating behavior, which could be understood as an attempt to deal with them or to distract them [12]. Heatherton and Baumeister [13] suggested a model, in which binge eating is seen as the result of an escape from unpleasant states, especially from "the awareness of the self's shortcomings, creating negative affects such as anxiety and depression" and represents a maladaptive way of coping. Fox and Power [10] also assume that emotions play a central role in all eating disorders. In their model, an eating disorder has the function of inhibiting emotions, in particular, negative emotions like anger and disgust. Only a few studies examined a broad range of emotional states in subjects with binge eating disorder and its relation to eating, although a more differentiated understanding of the term negative emotion is necessary to use research findings in everyday work with these patients. Arnow et al. [14] described anger and frustration preceding an urge to eat more often than sadness and depression. In their study, anger/frustration, anxiety and sadness/depression accounted for $95 \%$ of the antecedent moods preceding a binge. The Emotional Eating Scale (EES), which was subsequently developed [15] asks subjects to report on the intensity of an urge to eat under a range of possible negative emotional states (summarized to the three factors mentioned above). To our knowledge, there are no further studies. In people with alexithymia, negative emotions in the body-esteem seem to be associated with abnormal eating behaviors. Both self-esteem and body-esteem play a role in the pathogenesis of eating disorders. Abnormal eating behaviors may worsen self-esteem and the feelings about one's body [16]. The aims of the present study were to examine the central effect of alexithymia on anger, eating attitudes and self-esteem, which are closely related with emotional awareness and with each other, to determine the correlations of self-esteem, eating attitudes, anger and alexithymia with each-other, in the women who applied to the psychological counseling center.

\section{METHODS}

\section{Participants}

This study was conducted with 100 women counselors who applied to Counseling Center and were randomly selected. Our inclusion criterias are the absence of psychological and medical condition that could prevent them from responding to the questionnaires, and older than 18 years old. In the study, the average age of the group is 35.7 years and the age range is between $18-71$ years.

\section{Research Design}

The researcher introduced himself/herself before starting the data collection process and explained the 
purpose and content of the research. The respondents who agreed to participate in the survey explained how to fill the questionnaire. In the demographic form, participants were asked to respond to research questions, and participation in the survey was based on volunteerism. The survey participants were informed that this study was conducted to examine the relationship between alexithymia, eating attitude, selfesteem, and anger in adult individuals referred to Psychological Counseling Centers. All the answers given to the questions were kept confidential, and the scales were filled out, expressing that they could not be used except for scientific purposes. Each questionnaire was completed within 15-25 minutes. The study was approved by ethics committee from Üsküdar University.

\section{Measures}

\section{Demographic Information Form}

It was designed by the researcher to determine the participants' characteristics such as age, gender, education, marital status and economic level. In the last six months, there are also questions about whether treatment is due to a psychiatric/psychological problem.

\section{Toronto Alexithymia Scale (TAS-20)}

The five-point Likert-type scale consists of 20 items. There are subscales of difficulty in defining feelings (TAS-1), difficulty in identifying feelings (TAS-2) and outward thinking (TAS-3). High scores indicate high alexithymic level. Bagby et al. [17] developed the scale. Turkish adaptation was made by Güleç et al. [18]. The total scale was found to be 0.78 for Cronbach alpha and $0.57-0.80$ for subscales. According to confirmatory factor analysis results, the alexithymia structure has been shown to provide 3 factors.

\section{State-Trait Anger Expression Inventory (STAXI)}

Trait anger and anger expression style scale developed by Spielberger [19] was adapted into Turkish by Özer [20]. It is a self-assessment scale composed of thirty-four items. Ten items of this 34item scale determine trait anger and 24 items determine anger expression style (Anger-in, Anger-out and Anger control). High scores received from trait anger indicate high levels of anger; high scores from anger-in scale indicate suppressed anger; high scores from anger-out scale indicate easy expression of anger and high scores from anger control scale indicate controllability of anger. Internal consistency coefficients measured for the scale in its Turkish adaptation are 0.79 for trait anger dimension, 0.84 for control anger, 0.78 for anger out and 0.62 for anger suppression [20].

\section{Rosenberg Self-Esteem Scale (RSES)}

It consists of 63 items and 12 subscales of multiple choice [21]. Subjects are a measure of their filling. The validity and reliability study in our country was carried out by Çuhardaroğlu [22]. D4-Criticism, D5Depressive affect, D6-Dream establishment, D7-Psychosomatic manifestations, Self-esteem, D8Personal threat, D9-Discussion participation level, D10-Parent interest, D11-Parent relationship, D12Psychic isolation. Items belonging to other sub-scales other than the self-esteem sub-scale are evaluated according to the response key, and each score is given a '1' score. If self-esteem is sub-scale, the answers are evaluated between 0-6 points. A zero-one point is high, 2-4 points moderate, 5-6 points low self-esteem level.

\section{Eating Attitude Test (EAT)}

By Garner and Garfinkel [23]; is a self-reporting scale developed to evaluate possible eating disorders in both eating disorders and non-eating disorders. The scale consists of forty items, and the measurement is applied to sixty Likert types. Savaşır and Erol [24] conducted validity and realibility, but no cut-off score was calculated for Turkish form. The scale was used to evaluate eating attitudes in both groups of patients.

\section{Statistical Analysis}

The data were analyzed using the SPSS 15.00 Windows package program. After applying the Kolmogorov-Smirnov Normality Test, the Independent Sample T-Test, Independent Sample Oneway ANOVA, and Tukey Test were applied to the data showing normal distribution. Mann-Whitney U Test and Kruskal-Wallis T Test were applied to the data without normal distribution. Also, the Spearman Correlation Test was used to measure the severity of relations between variables. 


\section{RESULTS}

Of the 100 women who participated in the research; 23 women between the ages of 18-24, 22 women between the ages of 25-34, 38 women between the ages of 35-44, and 17 women over the age of 45 . Twenty-seven women weighed 55 kilograms or less, 31 women between 56 and 65 kilograms, 19 women between 66 and 75 kilograms, and 23 women over 76 kilograms. There were 31 female primary school graduates, six female secondary school graduates, 27 high school graduates, nine female university students, 27 female college or university graduates (Table 1).

\section{Correlation between Toronto Alexithymia Scale Sub-dimensions and Eating Attitude}

A Pearson correlation analysis revealed a weak positive correlation between difficulty in identifying feelings and eating attitude $(\mathrm{r}=0.21 ; p<0.05)$; it was observed that there was a weak positive relationship between difficulty in describing feelings and eating attitude $(\mathrm{r}=0.21 ; p<0.05)$, while the correlation between externally-oriented thinking and eating attitude were not significant $(\mathrm{r}=0.14 ; p>0.05)$ (Table 2).

\section{Correlation between Toronto Alexithymia Scale} Sub-dimensions with Rosenberg Self-esteem Subscales

A positive moderate relationship $(\mathrm{r}=0.34 ; p<$ 0.01 ) between difficulty in identifying feelings and self-esteem; there is a moderate relationship $(\mathrm{r}=0.35$; $p<0.01$ ) between the continuity of the self concept; a moderate relationship between Sensitivity to criticism $(\mathrm{r}=0.31 ; p<0.01)$; a moderate relationship $(\mathrm{r}=0.29$; $p<0.01)$ between the depressive mood and; a moderate relationship $(\mathrm{r}=0.29 ; p<0.01)$ between Visionary; a moderate relationship between psychosomatic symptoms $(\mathrm{r}=0.35 ; p<0.01)$; a weak relationship $(\mathrm{r}=0.23 ; p<0.05)$ between feeling threatened in interpersonal relationships; psychic isolation $(\mathrm{r}=0.38 ; p<0.01)$ correlations were found to be significant. Also relying on people $(\mathrm{r}=-0,03 ; p$ $>0.05)$; the Degree of participating in discussions ( $\mathrm{r}$ $=-0.06 ; p>0.05)$; Interest of parents $(\mathrm{r}=0.18, p<$ $0.01)$; Relationship with father $(\mathrm{r}=0.09 ; p>0.05)$ were not significant (Table 2).

A moderate relationship $(\mathrm{r}=0.27 ; p<0.01)$
Table 1. Distributions related to socio-demographic characteristics

\begin{tabular}{|c|c|c|c|}
\hline \multicolumn{2}{|c|}{$n=100$} & $\mathbf{n}$ & $\%$ \\
\hline \multirow{4}{*}{ Age (years) } & $18-24$ & 23 & 23 \\
\hline & $25-34$ & 22 & 22 \\
\hline & $35-44$ & 38 & 38 \\
\hline & Over 45 & 17 & 17 \\
\hline \multirow{4}{*}{ Weight (kg) } & Less than 55 & 27 & 27 \\
\hline & $56-65$ & 31 & 31 \\
\hline & $66-75$ & 19 & 19 \\
\hline & Over76 & 23 & 23 \\
\hline \multirow{5}{*}{ Education } & Primary school & 31 & 31 \\
\hline & Secondary school & 6 & 6 \\
\hline & High shool & 27 & 27 \\
\hline & College student & 9 & 9 \\
\hline & $\begin{array}{l}\text { Graduated form } \\
\text { university }\end{array}$ & 27 & 27 \\
\hline \multirow{4}{*}{ Marital status } & Maried & 63 & 63 \\
\hline & Single & 29 & 29 \\
\hline & Engaged & 2 & 2 \\
\hline & Divorced/Widow & 6 & 6 \\
\hline \multirow{8}{*}{$\begin{array}{l}\text { Monthly income } \\
\text { (Turkish Liras) }\end{array}$} & $0-500$ & 1 & 1 \\
\hline & $501-1000$ & 0 & 0 \\
\hline & $1001-1500$ & 5 & 5 \\
\hline & $1501-2000$ & 16 & 16 \\
\hline & $2001-2500$ & 35 & 35 \\
\hline & $2501-3000$ & 27 & 27 \\
\hline & $3001-3500$ & 12 & 12 \\
\hline & Over 3501 & 4 & 4 \\
\hline $\begin{array}{l}\text { Diagnosis from } \\
\text { psychologist or }\end{array}$ & No & 61 & 61 \\
\hline $\begin{array}{l}\text { psychiatrist in last } 6 \\
\text { months }\end{array}$ & Yes & 39 & 39 \\
\hline \multirow{2}{*}{ Drug usage status } & No & 65 & 65 \\
\hline & Yes & 35 & 35 \\
\hline
\end{tabular}

between difficulty in describing feelings and Sensitivity to criticism; a moderate relationship between psychosomatic symptoms $(\mathrm{r}=0.29$; $p<$ 0.01 ); a weak relationship between parental interest ( $\mathrm{r}$ $=0.22 ; p<0.05)$ and correlations were found to be significant. Also, self-esteem $(\mathrm{r}=0.17 ; p<0.05)$; continuity of the self-concept $(\mathrm{r}=0.20 ; p>0.05)$; relying on people $(\mathrm{r}=0.02 ; p>0.05)$; depressive $\operatorname{mood}(\mathrm{r}=0.11 ; p>0.05)$; visionary $(\mathrm{r}=0.16 ; p>$ $0.05)$; feeling threatened in interpersonal relationships $(\mathrm{r}=0.16 ; p>0.05)$; the degree of participating in discussions $(\mathrm{r}=-0,13 ; p>0.05)$; relationship with the father $(r=-0,04 ; p>0.05)$; relationship between psychic isolation $(\mathrm{r}=0.18 ; p>0.05)$ were not significant (Table 2). 
Table 2. Correlations of TAS-20 sub-scales with EAT, RSES, STAXI scores

\begin{tabular}{|c|c|c|c|c|}
\hline & & \multicolumn{3}{|c|}{$\begin{array}{c}\text { Toronto Alexithymia Scale } \\
\end{array}$} \\
\hline & & $\begin{array}{l}\text { Difficulties in } \\
\text { identifying } \\
\text { Feelings }\end{array}$ & $\begin{array}{c}\text { Difficulties in } \\
\text { Describing } \\
\text { Feelings }\end{array}$ & $\begin{array}{c}\text { Externally } \\
\text { Oriented } \\
\text { Thinking }\end{array}$ \\
\hline \multirow[t]{2}{*}{ Eating Attitude Test } & Eating Attitude & $\mathrm{r}=0.21$ & $\mathrm{r}=0.21$ & $r=0.14$ \\
\hline & & $p=0.04$ & $p=0.04$ & $p=0.17$ \\
\hline \multirow{24}{*}{$\begin{array}{l}\text { Rosenberg Self-Esteem } \\
\text { Scale }\end{array}$} & Self-Esteem & $\mathrm{r}=0.34$ & $\mathrm{r}=0.17$ & $\mathrm{r}=0.00$ \\
\hline & & $p<0.01$ & $p=0.08$ & $p=0.99$ \\
\hline & Continuity of self-concept & $\mathrm{r}=0.35$ & $\mathrm{r}=0.20$ & $\mathrm{r}=0.15$ \\
\hline & & $p<0.01$ & $p=0.051$ & $p=0.14$ \\
\hline & Relying on people & $r=-0.03$ & $\mathrm{r}=0.02$ & $\mathrm{r}=-0.11$ \\
\hline & & $p=0.73$ & $p=0.84$ & $p=0.26$ \\
\hline & Sensitivity to criticism & $\mathrm{r}=0.31$ & $\mathrm{r}=0.27$ & $\mathrm{r}=0.23$ \\
\hline & & $p<0.01$ & $p=0.008$ & $p=0.02$ \\
\hline & Depressive mood & $\mathrm{r}=0.29$ & $\mathrm{r}=0.11$ & $\mathrm{r}=-0.01$ \\
\hline & & $p<0.01$ & $p=0.28$ & $p=0.90$ \\
\hline & Visionary & $\mathrm{r}=0.29$ & $\mathrm{r}=0.16$ & $\mathrm{r}=-0.02$ \\
\hline & & $p<0.01$ & $p=0.10$ & $p=0.85$ \\
\hline & Psychosomatic symptoms & $\mathrm{r}=0.35$ & $\mathrm{r}=0.29$ & $\mathrm{r}=0.24$ \\
\hline & & $p<0.01$ & $p<0.01$ & $p=\mathbf{0 . 0 2}$ \\
\hline & Feeling threatened in & $r=0.23$ & $\mathrm{r}=0.16$ & $\mathrm{r}=0.12$ \\
\hline & interpersonal relationships & $p=0.02$ & $p=0.10$ & $p=0.23$ \\
\hline & Degree of participating in & $\mathrm{r}=-0.06$ & $\mathrm{r}=-0.13$ & $r=-0.16$ \\
\hline & discussions & $p=0.58$ & $p=0.18$ & $p=0.11$ \\
\hline & Interest of parents & $\mathrm{r}=0.18$ & $\mathrm{r}=0.22$ & $\mathrm{r}=0.30$ \\
\hline & & $p=0.08$ & $p=\mathbf{0 . 0 3}$ & $p<0.01$ \\
\hline & Relationship with father & $r=0.09$ & $\mathrm{r}=-0.04$ & $r=-0.04$ \\
\hline & & $p=0.36$ & $p=0.71$ & $p=0.72$ \\
\hline & Psychic isolation & $\mathrm{r}=0.38$ & $\mathrm{r}=0.18$ & $\mathrm{r}=0.32$ \\
\hline & & $p<0.01$ & $p=0.07$ & $p<0.01$ \\
\hline \multirow[t]{2}{*}{ Trait Anger Scale } & Trait Anger & $\mathrm{r}=0.30$ & $\mathrm{r}=0.30$ & $\mathrm{r}=0.05$ \\
\hline & & $p<0.01$ & $p<0.01$ & $p=0.60$ \\
\hline \multirow[t]{6}{*}{ Anger Expression Styles } & Anger-Control & $r=-0.04$ & $\mathrm{r}=-0.12$ & $r=-0.13$ \\
\hline & & $p=0.70$ & $p=0.24$ & $p=0.19$ \\
\hline & Anger-Out & $\mathrm{r}=0.22$ & $\mathrm{r}=0.34$ & $\mathrm{r}=0.04$ \\
\hline & & $p=0.02$ & $p<0.01$ & $p=0.68$ \\
\hline & Anger-In & $\mathrm{r}=0.16$ & $\mathrm{r}=0.10$ & $\mathrm{r}=-0.08$ \\
\hline & & $p=0.11$ & $p=0.32$ & $p=0.46$ \\
\hline
\end{tabular}

EAT $=$ Eating Attitudes Test, STAXI = State-Trait Anger Expression Inventory, RSES = Rosenberg Self-Esteem Scale, TAS $=$ Toronto Alexithymia Scale

A weak relationship $(\mathrm{r}=0.23 ; p<0.05)$ between externally oriented thinking and sensitivity to criticism; a weak relationship $(\mathrm{r}=0.24 ; p<0.05)$ between psychosomatic symptoms; a moderate relationship ( $\mathrm{r}=0.30 ; p<0.01)$ between the interest of parents; a moderate relationship $(\mathrm{r}=0.32 ; p<0.01)$ between psychic isolation were found to be significant. Also self-esteem $(\mathrm{r}=0 ; p>0.05)$; continuity of the self-concept $(\mathrm{r}=0.15 ; p>0.05)$; relying on people $(\mathrm{r}=-0.11 ; p>0.05)$; depressive $\operatorname{mood}(\mathrm{r}=-0.01 ; p>0.05)$; visionary $(\mathrm{r}=-0,02 ; p>$ $0.05)$; feeling threatened in interpersonal relationships $(\mathrm{r}=0.12 ; p>0.05)$; the degree of participating in discussions $(\mathrm{r}=-0,16 ; p>0.05)$; relationship with father $(\mathrm{r}=-0.04 ; p>0.05)$ were not significant (Table 2).

Correlation between the Toronto Alexithymia Scale Sub-dimensions with State-Trait Anger Expression Inventory Sub-dimensions

A moderate relationship between the difficulty in identifying feelings and the trait anger $(\mathrm{r}=0.30 ; p$ $<.01)$; A weak relationship between anger-out $(\mathrm{r}=$ $0.22, p<0.05)$ were observed and the correlations 
Table 3. Correlations of EAT with RSES and STAXI Scores

\begin{tabular}{|c|c|c|}
\hline & & $\begin{array}{c}\text { Eating } \\
\text { Attitude } \\
\text { Test } \\
\end{array}$ \\
\hline \multirow{11}{*}{$\begin{array}{l}\text { Rosenberg } \\
\text { Self-Esteem } \\
\text { Scale }\end{array}$} & Self-Esteem & $\begin{array}{l}\mathrm{r}=0.18 \\
p=0.08\end{array}$ \\
\hline & Continuity of self-concept & $\begin{aligned} \mathrm{r} & =0.20 \\
\boldsymbol{p} & =\mathbf{0 . 0 4 9}\end{aligned}$ \\
\hline & Relying on people & $\begin{array}{l}r=-0.14 \\
p=0.17\end{array}$ \\
\hline & Sensitivity to criticism & $\begin{array}{l}\mathrm{r}=0.16 \\
p=0.12\end{array}$ \\
\hline & Depressive mood & $\begin{array}{l}\mathrm{r}=0.09 \\
p=0.39\end{array}$ \\
\hline & Visionary & $\begin{array}{c}\mathrm{r}=0.20 \\
\boldsymbol{p}=\mathbf{0 . 0 4 5}\end{array}$ \\
\hline & Psychosomatic symptoms & $\begin{array}{l}\mathrm{r}=0.11 \\
p=0.28\end{array}$ \\
\hline & $\begin{array}{l}\text { Feeling threatened in } \\
\text { interpersonal relationships } \\
\text { Degree of participating in } \\
\text { discussions }\end{array}$ & $\begin{array}{l}\mathrm{r}=0.23 \\
\boldsymbol{p}=\mathbf{0 . 0 2} \\
\mathrm{r}=-0.13 \\
p=0.21\end{array}$ \\
\hline & Interest of parents & $\begin{array}{l}\mathrm{r}=0.01 \\
p=0.93\end{array}$ \\
\hline & Relationship with father & $\begin{array}{l}\mathrm{r}=-0.10 \\
p=0.35\end{array}$ \\
\hline & Psychic isolation & $\begin{array}{l}\mathrm{r}=0.09 \\
p=0.37\end{array}$ \\
\hline $\begin{array}{l}\text { Trait Anger } \\
\text { Scale }\end{array}$ & Trait Anger & $\begin{array}{l}\mathrm{r}=0.24 \\
\boldsymbol{p}=\mathbf{0 . 0 2}\end{array}$ \\
\hline & Anger-Control & $\begin{array}{l}\mathrm{r}=0.00 \\
p=0.97\end{array}$ \\
\hline Expression & Anger-Out & $\begin{array}{l}\mathrm{r}=0.05 \\
p=0.61\end{array}$ \\
\hline & Anger-In & $\begin{array}{l}\mathrm{r}=0.16 \\
p=0.11\end{array}$ \\
\hline
\end{tabular}

EAT $=$ Eating Attitudes Test, STAXI $=$ State-Trait Anger Expression Inventory, RSES $=$ Rosenberg Self-Esteem Scale

were found to be significant. Furthermore, correlations with anger-control $(\mathrm{r}=-0,04 ; p>0.05)$; and anger-in $(\mathrm{r}=0.16 ; p>0.05)$ were not significant (Table 2$)$.

A moderate relationship between the difficulty in describing feelings and trait anger $(\mathrm{r}=0.30 ; p<0.01)$; anger-out $(\mathrm{r}=0.34, p<0.01)$ were observed and the correlations were found significant. Furthermore, relationships wiht anger-control $(\mathrm{r}=-0,12 ; p>0.05)$; anger-in $(\mathrm{r}=0.10 ; p>0.05)$ were not significant (Table 2).

Relationships between externally oriented thinking with trait anger $(\mathrm{r}=0.05 ; \mathrm{p}>0.05)$; angercontrol ( $\mathrm{r}=-0,13 ; p>0.05)$; anger-out $(\mathrm{r}=0.04 ; p>$ $0.05)$; anger-in $(\mathrm{r}=-0.08 ; p>0.05)$ were not significant (Table 2).
Correlation between Eating Attitude with Rosenberg Self-esteem Subscales

A weak relationship $(\mathrm{r}=0.20 ; p<0.05)$ was found between the eating attitude and the continuity of the self-concept; a weak relationship $(\mathrm{r}=0.20 ; p<0.05)$ between visionary; a weak relationship $(\mathrm{r}=0,23 ; p<$ 0.05 ) between feelings threatened in interpersonal relationships and correlations were found to be significant. Also, self-esteem $(\mathrm{r}=0.18, p>0.05)$; relying on people $(\mathrm{r}=-0.14 ; p>0.05)$; sensitivity to criticism $(\mathrm{r}=0.16 ; p>0.05)$; depressive mood $(\mathrm{r}=$ $0.09 ; p>0.05)$; psychosomatic symptoms $(\mathrm{r}=0.11 ; p$ $>0.05)$; the degree of participating in discussion $(\mathrm{r}=$ $-0,13 ; p>0.05)$; interest of parents $(\mathrm{r}=0.01 ; p>0.05)$; relationship with father $(\mathrm{r}=-0,10 ; p>0.05)$; psychic isolation $(\mathrm{r}=0.09 ; p>0.05)$ were not significant (Table 3).

\section{Correlation between Eating Attitude and State-} Trait Anger Expression Inventory Sub-dimensions

It was observed that there was a weak relationship between eating attitude and trait anger $(\mathrm{r}=0.24, p<$ 0.05 ) and the correlation was found to be significant. In addition, correlations with anger-control $(\mathrm{r}=0 ; p>$ $0.05)$; anger-out $(\mathrm{r}=0.05, p>0.05)$ and anger-in ( $\mathrm{r}=$ $0.16 ; p>0.05$ ) were not significant (Table 3 ).

\section{DISCUSSION}

Alexithymia is a personality construct that involves difficulties in identifying feelings, in describing feelings, and an externally oriented thinking style [17]. This construct was initially introduced to describe clinical patients with so-called psychosomatic diseases who experienced difficulties describing their emotions and who presented impoverished mental representations of their emotional states. This may explain the high prevalence of alexithymia in somatic and mental disorders [25]. The association of alexithymia with somatic symptoms in all aspects may also be considered in accordance with the literature.

When we look at the research done in this matter; individuals with higher alexithymia scores seem to have lower self-esteem. As scores of alexithymia increase, self-esteem scores decrease [26, 27]. The social interactions that develop together with low self 
esteem are threatening and the process of deterioration in social relations becomes more prominent [28]. It is known that alexithymic people apparently live in harmony with the environment, but they are in fact known to have little relation to their spiritual realities. The alexithymic person has a structure that can not express itself in society [29, 30]. Individuals with alexithymic structure were more likely to have insecure attachment style [31], which is a way of expressing themselves in society. In line with these results; it is thought that shyness causes the person to be distressed by the anxiety to be in a difficult situation against the people and supports the formation of an alexithymic structure.

Alexithymia was also thought to be related to lack of confidence and self-esteem [26]. A study of adolescents by Sayar et al. [27] found that depression and anxiety levels were significantly higher than those without alexithymic adolescents, but that self-esteem was significantly lower.

When the relationship between alexithymia and anger is examined; it was observed that there was a meaningful relationship between difficulty in expressing difficulties and describing feelings between trait anger and anger-out. Individuals with a high score of alexithymia are more likely to feel anger; introspection and irrelevant reactions tend to be more frequent in interpersonal relationships [3, 32, 33].

In the literature search; it is possible to say that all of these findings with anger are related to the alexithymia with high levels. Berenbaum and Irvin [3] reported that alexithymic individuals experienced more anger than non-alexithymic individuals, even so they use non-verbal expressions, because of difficulty in expressing feelings. And also; they point out that these persons have escaped from conflict. Similarly, there are also different studies that show the relationship between alexithymia and introverted anger [34], as well as the relationship between alexithymia and aggression [33].

One of the behaviors associated with anger is aggression. Fossati et al. [33] argue that insecure attachment and alexithymia together are significantly associated with impulsive aggression. Bekker et al. [35] found that antisocial behavior, a component of alexithymia, is negatively related to antisocial behavior. As we have already pointed out, in a study, alexithymic individuals showed more anger and aggression as well as more psychological symptoms such as anxiety, depression, negative self, somatization [3]. It is also consistent with the literature that our results, especially difficulties in describing and identifying feelings, are related to persistent angry and outrage.

Not defining or expressing a feeling does not cause it to disappear. As a solution to these people, the emotions are turned into anger. The first level solution becomes a second level problem. In our research; it was seen that there was a meaningful relationship between anger with eating attitudes as well as difficulties in identifying and describing feelings.

Recent anger-related studies have shown that anger and aggression are associated with eating disorders. It is also stated that it is one of the basic features of psychopathology [36]. It is reported that patients with eating disorders are less aware of their anger, and have difficulty in describing and expression of feelings [37]. Interesting part of our study, difficulty in describing and identifying of feelings was related to continuous anger and outrage feelings, as well as with eating disorders, but eating attitudes was associated only with persistent anger. It is consistent with literature, because lack of expression of anger is the other source of problematic eating attitudes. Studies of eating disorders seem to focus specifically on women. It is reported that these patients have more anger attacks compared to normals, that their anger is mostly state anger, and that women who have an eating disorder have high-suppressed anger [38]. And also; there is a view that the anger influences women's excessive eating habits [39]. Thompson et al. [40] argue that the anorexic or bulimic attitudes of adolescents are an expression of unexpressed anger towards their parents. Adolescents view the amount of food as the only thing their parents can not control. As has been pointed out in previous studies, the frequency of eating disorders in recent years has also increased in eastern countries [41, 42].

In general, the most basic step in one's life is the awareness of its feelings [43, 44]. The level of emotional awareness and ability to cope with these emotions determines their subsequent cognitive and behavioral attitudes [45]. When feelings are not identified and expressed, the tension we are experiencing can turn into anger. Anger then begins to shape our own cognitive and behavioral attitudes. If it 
can be expressed, it can turn into an aggressive behavior and pave the way for the formation of some cognitive attitudes. We can evaluate the results of our work from this perspective. The low awareness of emotions can also shape our need to avoid encountering it as it causes it to turn into anger [46]. We can also evaluate the relevance of the sensitivity to criticism in our self-respect to all the alexithymia subscales from this perspective. Our unexpressed feelings find a way to express themselves in a way. One of the most concrete signs of this is somatic complaints [47]. Another finding in our study is consistent with studies in the literature related to alexithymia and somatic complaints. Anger results in two ways in the person; "to express" or "not to express." According to our results, unexpressed feelings are related to eating attitudes, as well as both trait anger and anger-out. However, while eating attitudes were related to trait anger, there were not associated with anger-out. It was also emphasized that the studies were related to the relationship of eating disorders with anger that is repressed and unexpressed and eating attitudes act as an expression of the indefinable anger [48]. In this sense, results are compatible with the studies in the literature.

\section{The Limitations of the Study}

Our work was conducted among women in psychological counseling centers provided free counseling by the municipality. Because the socioeconomic level is limited to a low population, it caused a shortage of interpretation of the data. It can also be applied in subsequent studies, with emotion regulation related scales and with larger populations. Further prospective studies are needed the highlight the role of emotional awareness in understanding the cause-and-effect relationship.

\section{CONCLUSION}

Our study has dealt with many known associations in a single study. We can use a wide variety of scales to understand patients. But sometimes when we are dealing with parts, we can not see the whole thing. Self-esteem, anger and eating attitudes are cognitive, emotional, and behavioral aspects of a person. We can separate these features or interpret them as a reflection of a problem in different layers. We wanted to evaluate the results of this work by opening a different window for future work. According to these results, we can interpret that the relations of alexithymia with anger, with the eating attitudes of the anger, with the selfesteem of the eating attitudes and with the alexithymia of the self-esteem are not spontaneous relations, they are all parts of a continuum and a general structure. We can interpret it as the establishment of cause-effect relations in more different layers than these relations occur in local interactions. The results of the study suggest that alexithymia, which is the most fundamental layer, can indirectly change many cognitive, emotional and behavioral outcomes that related to anger, eating attitudes and self-esteem in the struggle with problems.

\section{Conflict of interest}

The authors disclosed no conflict of interest during the preparation or publication of this manuscript.

\section{Financing}

The authors disclosed that they did not receive any grant during conduction or writing of this study.

\section{REFERENCES}

[1] Levenson H. Time-Limited Dynamic Psychotherapy: A Guide to Clinical Practice. New York: Basic Books, 1995.

[2] Taylor GJ, Bagby RM, Parker JD. The alexithymia construct. A potential paradigm for psychosomatic medicine. Psychosomatics 1991;32:153-64.

[3] Berenbaum H, Irvin S. Alexithymia, anger, and interpersonal behavior. Psychother Psychosom 1996;65:203-8.

[4] Forgays DG, Forgays DK, Spielberger CD. Factor Structure of the State-Trait Anger Expression Inventory. J Pers Assess 1997;69:497-507. [5] Loas G, Fremaux D, Otmani O, Lecercle C, Delahousse J. Is alexithymia a negative factor for maintaining abstinence? A follow-up study. Compr Psychiatry 1997;38:296-9.

[6] Gratz KL, Roemer L. The relationship between emotion dysregulation and deliberate self-harm among female undergraduate students at an urban commuter university. Cogn Behav Ther 2008;37:1425.

[7] Velotti P, Garofalo C, Petrocchi C, Cavallo F, Popolo R, Dimaggio G. Alexithymia, emotion dysregulation, impulsivity and aggression: A multiple mediation model. Psychiatry Res 2016;237:296-303.

[8] Wahlstrom LC, Scott JP, Tuliao AP, DiLillo D, McChargue DE. Posttraumatic stress disorder symptoms, emotion dysregulation, and aggressive behavior among incarcerated methamphetamine users. J Dual Diagn 2015;11:118-27.

[9] Stice E. Risk and maintenance factors for eating pathology: a metaanalytic review. Psychol Bull 2002;128:825-48.

[10] Fox JRE, Power MJ. Eating disorders and multi-level models of 
emotion: an integrated model. Clin Psychol Psychother 2009;16:24067.

[11] Zeeck A, Stelzer N, Linster HW, Joos A, Hartmann A. Emotion and eating in binge eating disorder and obesity. Eur Eat Disord Rev 2011;19:426-37.

[12] Stice E. Interactive and mediational etiologic models of eating disorder onset: evidence from prospective studies. Annu Rev Clin Psychol 2016;12:359-81.

[13] Heatherton TF, Baumeister RF. Binge eating as escape from selfawareness. Psychol Bull 1991;110:86-108.

[14] Arnow B, Kenardy J, Agras WS. Binge eating among the obese: a descriptive study. J Behav Med 1992;15:155-70.

[15] Arnow B, Kenardy J, Agras WS. The emotional eating scale: the development of a measure to assess coping with negative affect by eating. Int J Eat Disord 1995;18:79-90.

[16] Sasai K, Tanaka K, Hishimoto A. Alexithymia and its relationships with eating behavior, self esteem, and body esteem in college women. Kobe J Med Sci 2011;56:E231-8.

[17] Bagby RM, Taylor GJ, Parker JDA. The twenty-item Toronto Alexithymia scale-II. Convergent, discriminant, and concurrent validity. J Psychosom Res 1994;38:33-40.

[18] Güleç H, Köse S, Güleç MY, Çitak S, Evren C, Borckardt J, et al. Reliability and factorial validity of the Turkish version of the 20-item Toronto alexithymia scale (TAS-20) Klinik Psikofarmakoloji Bulteni 2009;19:213-9.

[19] Spielberger CD. State-Trait Anger Expression Inventory. Hoboken, NJ, USA: John Wiley \& Sons, Inc; 2010. p1.

[20] Özer AK. Öfke, kaygı ve depresyon eğlimlerinin biliss,el alt yapısıyla ilgili bir çalışma. Turk Psikolojisi Dergisi 1994;9:15-25. [Article in Turkish]

[21] Rosenberg M. Society and the Adolescent Self-Image. NJ: Princeton University Pres, Princeton; 1965.

[22] Çuhadaroğlu F. [Self-esteem in adolescence]. Unpublished doctoral dissertation, Hacettepe University, Ankara, Turkey. [Article in Turkish] [23] Garner DM, Garfinkel PE. The Eating Attitudes Test: an index of the symptoms of anorexia nervosa. Psychol Med 1979;9:273-9.

[24] Savaşır I, Erol N. Yeme Tutum Testi: Anoreksiye nervoza belirtiler endeksi. Turk Psikoloji Dergisi 1989;7:19-25. [Article in Turkish] [25] Lumley MA, Neely LC, Burger AJ. The assessment of alexithymia in medical settings: implications for understanding and treating health problems. J Pers Assess 2007;89:230-46.

[26] Zimmermann G, Rossier J, De Stadelhofen FM, Gaillard F. Alexithymia assessment and relations with dimensions of personality. Eur J Psychol Assess 2005;21:23-33.

[27] Sayar K, Kose S, Grabe HJ, Topbas M. Alexithymia and dissociative tendencies in an adolescent sample from Eastern Turkey. Psychiatry Clin Neurosci 2005;59:127-34.

[28] Dreessen L, Arntz A, Hendriks T, Keune N, van den Hout M. Avoidant personality disorder and implicit schema-congruent information processing bias: a pilot study with a pragmatic inference task. Behav Res Ther 1999;37:619-32.

[29] Evren EC, Can S, Evren B, Çakmak D. The relationship between alexithymia and depression, anxiety and erectile dysfunction in a sample of male alcoholic inpatients: A controlled study. Klinik Psikofarmakoloji Bulteni 2002;12:165-73.

[30] Graugaard PK, Holgersen K, Finset A. Communicating with alexithymic and non-alexithymic patients: an experimental study of the effect of psychosocial communication and empathy on patient satisfaction. Psychother Psychosom 2004;73:92-100.

[31] Oskis A, Clow A, Hucklebridge F, Bifulco A, Jacobs C, Loveday C. Understanding alexithymia in female adolescents: The role of attachment style. Pers Individ Dif 2013;54:97-102.

[32] Teten AL, Miller LA, Bailey SD, Dunn NJ, Kent TA. Empathic deficits and alexithymia in trauma-related impulsive aggression. Behav Sci Law 2008;26:823-32.

[33] Fossati A, Acquarini E, Feeney JA, Borroni S, Grazioli F, Giarolli LE, et al. Alexithymia and attachment insecurities in impulsive aggression. Attach Hum Dev 2009;11:165-82.

[34] Sayar K, Gulec H, Topbas M. Alexithymia and anger in patients with fibromyalgia. Clin Rheumatol 2004;23:441-8.

[35] Bekker MHJ, Bachrach N, Croon MA. The relationships of antisocial behavior with attachment styles, autonomy-connectedness, and alexithymia. J Clin Psychol 2007;63:507-27.

[36] Krug I, Bulik CM, Vall-Llovera ON, Granero R, Agüera Z, Villarejo $\mathrm{C}$, et al. Anger expression in eating disorders: Clinical, psychopathological and personality correlates. Psychiatry Res 2008;161:195-205.

[37] Miotto P, Pollini B, Restaneo A, Favaretto G, Preti A. Aggressiveness, anger, and hostility in eating disorders. Compr Psychiatry 2008;49:364-73.

[38] Geller J, Cockell SJ, Hewitt PL, Goldner EM, Flett GL. Inhibited expression of negative emotions and interpersonal orientation in anorexia nervosa. Int J Eat Disord 2000;28:8-19.

[39] Feinson MC, Hornik-Lurie T. Binge eating \& childhood emotional abuse: The mediating role of anger. Appetite 2016;105:487-93.

[40] Thompson KA, Kelly NR, Schvey NA, Brady SM, Courville AB, Tanofsky-Kraff M, et al. Internalization of appearance ideals mediates the relationship between appearance-related pressures from peers and emotional eating among adolescent boys and girls. Eat Behav 2017;24:66-73.

[41] Nasser M. Eating disorders across cultures. Psychiatry 2009;8:34750 .

[42] Bilali A, Galanis P, Velonakis E, Katostaras T. Factors associated with abnormal eating attitudes among Greek adolescents. J Nutr Educ Beha 2010;42:292-8.

[43] Heck A, Hock A, White H, Jubran R, Bhatt RS. Further evidence of early development of attention to dynamic facial emotions: Reply to Grossmann and Jessen. J Exp Child Psychol 2017;153:155-62.

[44] Lyons M, Hughes S. Feeling me, feeling you? Links between the Dark Triad and internal body awareness. Pers Individ Dif 2015;86:30811.

[45] Sharpe E, Wallis DJ. Attitudes towards emotional expression, emotion regulation and eating psychopathology. Appetite 2014;83:354.

[46] Shin M-K, Eom JY. Study on the alexithymia and anger in the Korean college students. Advanced Science and Technology Letters (Healtcare and Nursing) 2015;116:189-95.

[47] Erkic M, Bailer J, Fenske SC, Schmidt SNL, Trojan J, Schröder A, et al. Impaired emotion processing and a reduction in trust in patients with somatic symptom disorder. Clin Psychol Psychother 2018;25:16372.

[48] Eom JY, Shin M-K. Relation of alexithymia, anger and binge eating behavior. Int J Bio-Sci Bio-Technol 2016;8:63-70. 